\title{
An Investigation into the Dissolution Characteristics of $\gamma$ Precipitates in Mg-3Al-Zn Alloy
}

\author{
Javad Mohammadi ${ }^{a *}$, Marjan Ghoreishi ${ }^{b}$, Yashar behnamian $^{c}$ \\ ${ }^{a}$ Department of Materials Science and Engineering, Science and Research Branch, Islamic Azad \\ University, Tehran, Iran \\ ${ }^{b}$ Azad University of Isfahan, Isfahan, Iran \\ ${ }^{c}$ Department of Chemical and Materials Engineering University of Alberta, Alberta, Canada \\ Received: January 8, 2014; Revised: June 10, 2014
}

\begin{abstract}
In non-equilibrium conditions, the coring phenomena may occur in the $\alpha-\mathrm{Mg}$ solid solution and $\gamma-\mathrm{Mg}_{17} \mathrm{Al}_{12}$ phase forms in the microstructure of $\mathrm{AZ}$ magnesium alloy series. This eutectic phase may introduce detrimental effect on workability of wrought alloys. In the present work, the dissolution characteristics of $\gamma$ phase have been investigated in AZ31 wrought magnesium alloy. Considering the eutectic temperature of AZ31 alloy, the homogenization treatment was executed in temperature range of 300-437 ${ }^{\circ} \mathrm{C}$ (i.e., somewhat below eutectic melting temperature of $\gamma$ precipitate) and 437$500{ }^{\circ} \mathrm{C}$ (i.e., higher eutectic melting temperature of $\gamma$ precipitate) for different durations. A thorough microstructural investigation and also thermodynamic calculations were executed. The results indicated that the dissolution rate of $\gamma$ phase is very low even at temperatures just below the eutectic point of the alloy, whereas it dramatically increases at temperatures higher than eutectic point. Moreover, it is suggested that partial melting of $\gamma$ phase due to eutectic melting reaction $(\alpha+\gamma \rightarrow \mathrm{L})$ may lead to reduced formability.
\end{abstract}

Keywords: AZ31, homogenization, $M g_{1} A l_{12}$, eutectic melting, workability

\section{Introduction}

As the lightest structural metallic material, magnesium alloys not only hold low density (almost two-thirds of aluminum), but also possess high specific strength, excellent damping and good ecology properties (easy to recycle and abundant in resources). Owing to these desirable properties, magnesium alloys are attractive in electronic, aeronautical and transportation industries ${ }^{1-3}$. Accordingly a thorough investigation of high temperature plastic deformation behavior of magnesium alloys is highly necessitated. This may assist enhancing the alloy workability which in turn plays an essential role in the industrialization of component fabrication. Among magnesium alloys, AZ31, as the most common wrought magnesium alloy, is of particular interest because of the good balance of strength and ductility. A number of previous investigations have studied hot formability of this alloy under specified conditions ${ }^{4-7}$. These researches made many attempts to develop suitable deformation condition for AZ31 alloy. In fact the important thermomechanical parameters such as temperature, strain rate and deformation ratio were considered, and yet less attention has been paid to the effects of second phase particles in initial microstructure.

AZ31 alloy may contain a small fraction of $\gamma-\mathrm{Mg}_{17} \mathrm{Al}_{12}$ particles (as a part of eutectic transformation) distributing either in grain interiors or along grain boundaries. Dissolution Rate of $\gamma$ phase is very low even at temperature just below the eutectic point of the alloy ${ }^{8}$. Some researches have been reported the detrimental effect of these particles

*e-mail: j.mohammadi.f@gmail.com at low temperatures ${ }^{9,10}$. Moreover, considering the reported eutectic reaction temperature $\left(\sim 437{ }^{\circ} \mathrm{C}\right)^{11}$ and also the melting point of $\gamma$ particles $\left(\sim 462{ }^{\circ} \mathrm{C}\right)^{12}$, the presence of $\gamma$ phase may possibly introduce a significant detrimental effect on high temperature mechanical response of AZ31 magnesium alloy.

As the wrought magnesium alloys are usually homogenized before applying any manufacturing process, in the present work dissolution characteristics of $\gamma$ phase were studied in AZ31 Mg alloy. This was carried out applying homogenization treatment at temperatures below and higher than that of eutectic point of the alloy. To assist explaining dissolution kinetic of $\gamma$ phase, differential thermal analysis, microstructural investigation and thermodynamic calculations were employed.

\section{Experimental Procedure}

An AZ31 magnesium alloy Mg-2.9\%Al-0.85\%Zn$0.3 \% \mathrm{Mn}$ (All in wt. \%) was selected as the experimental material. This was received as-hot rolled plates with $22 \mathrm{~mm}$ thickness. The alloy initial back scattered SEM microstructure is shown in Fig. 1. From this the existence of the second phase particles is realized. Energy dispersive spectroscopy (EDS) results indicate that the second phases (i.e., $\gamma-\mathrm{Mg}_{17} \mathrm{Al}_{12}$ as well as few particles of Al-Mn compounds) are distributed either in grain interiors or along grain boundaries (Figure $1 \mathrm{~b}$ and $\mathrm{c}$ ). To determine the characteristics of $\gamma$ precipitates, differential thermal analysis (DTA) was performed at $5 \mathrm{k} / \mathrm{min}$ heating/cooling rate. The 


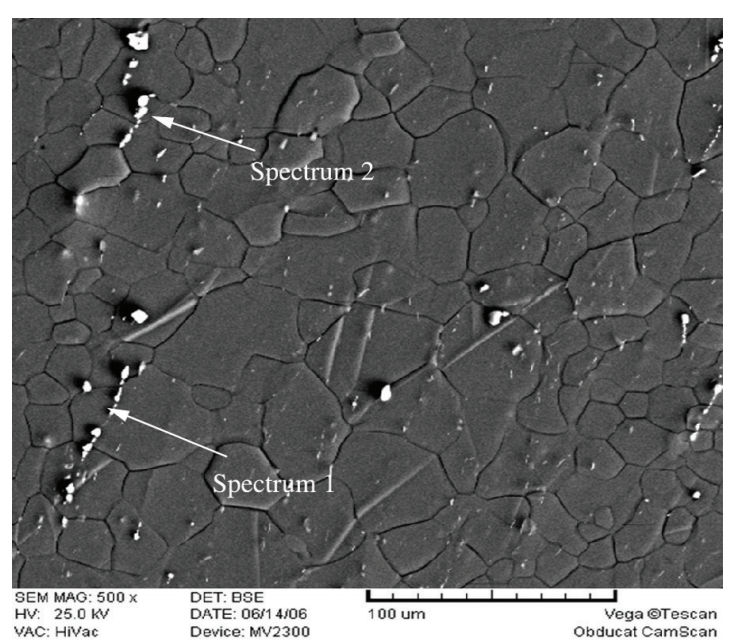

(a)
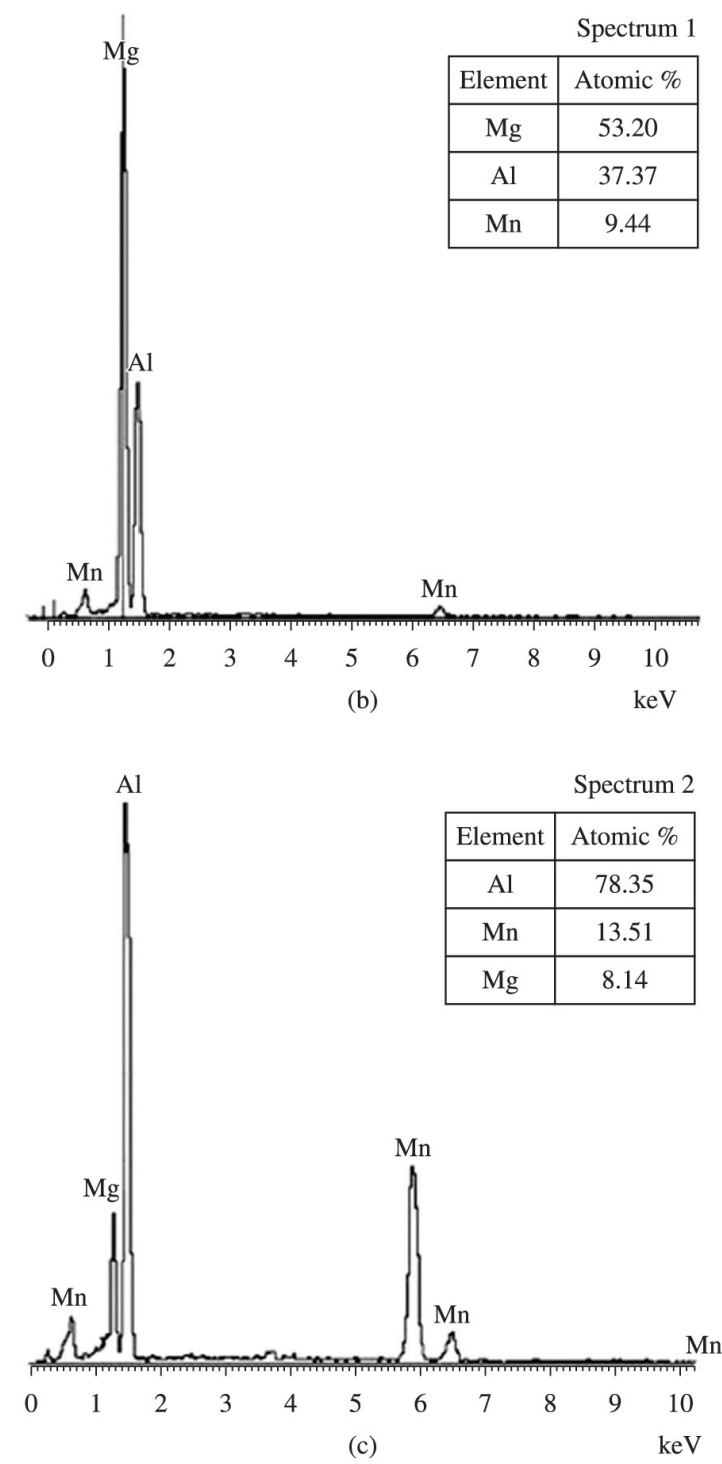

Figure 1. (a) The SEM image of the as-received experimental alloy, (b) EDS result of $\gamma$ precipitates, and (c) EDS result of $\mathrm{Al}_{6} \mathrm{Mn}$ compounds. size and distribution of Al-Mn intermetallic compounds were not affected by the homogenization treatment due to their high temperature melting $\left(\sim 705^{\circ} \mathrm{C}\right)$, which is well higher than the temperature range of thermo-mechanical processing of the magnesium alloy $\left(250-450{ }^{\circ} \mathrm{C}\right)^{2}$.

Considering the eutectic temperature of experimental alloy, the homogenization treatment was executed in temperature ranges of $300-437{ }^{\circ} \mathrm{C}$ (below the eutectic invariant temperature of $\gamma$ phase) and $437-500{ }^{\circ} \mathrm{C}$ (higher than the eutectic invariant temperature of $\gamma$ phase). Homogenization treatment was performed in a resistance furnace at $420^{\circ} \mathrm{C}$ for $3,6,12 \mathrm{hr}$ and also at $450,475^{\circ} \mathrm{C}$ for $5 \mathrm{~min}$. Homogenization times were adopted based on the low kinetics rate of the process below eutectic temperature ${ }^{8}$ and the related thermodynamic calculation at temperatures higher than eutectic point. The specimens with size of $8 \mathrm{~mm} \times 8 \mathrm{~mm} \times 1.5 \mathrm{~mm}$ were used to facilitate the fast heating response. The specimens were immediately water quenched right at the end of homogenization treatment. To reveal the obtained microstructure, the specimens were prepared using standard metallographic methods. The microstructural observation was performed at the center and mid-height of the treated specimens.

\section{Results and Discussion}

Figure 2 shows the microstructure of homogenized specimens at $420{ }^{\circ} \mathrm{C}$ for different homogenization times. In the initial equiaxed microstructure of the as-received alloy (Figure 2a) many twins are observed. This surely indicates the occurrence of twining during previous rolling schedule. The initial grain size was measured to be about $11 \mu \mathrm{m}$. As is seen in Figures $2 \mathrm{~b}$ and c, after homogenization for 3 and $6 \mathrm{hr}$ at $420{ }^{\circ} \mathrm{C}$ the twins are completely disappeared, but a significant amount of $\gamma$ phase particles remains the same in appearance. The latter confirms that the dissolution, which is governed by solid state diffusion, is a very slow process at this temperature. However, increasing the homogenization time to $12 \mathrm{hr}$ at $420{ }^{\circ} \mathrm{C}$ results in dissociation of $\gamma$ phases in $\alpha-\mathrm{Mg}$ matrix where a noticeably grain growth is observed (Figure 2d). Therefore, it is concluded that the dissolution rate of divorced $\gamma$ phase is very slow even at temperature just below (and very close to) the eutectic point of the alloy.

Figure $3 \mathrm{a}$ demonstrates the microstructure of the alloy treated at $450{ }^{\circ} \mathrm{C}$ for $5 \mathrm{~min}$. The occurrence of incipient melting within the $\gamma$ particles is evident. This may imply to the initiation of a local melting due to the reaction of the small $\gamma$ phase particles with the surrounding $\alpha$ phase region. Providing more time, this incipient melting will be extended to the whole $\gamma$ particles.

To determine the characteristics of $\gamma$ precipitates and to assist explaining the dissolution rate of this eutectic phase, differential thermal analysis (DTA) was also performed. The thermal analysis curve of the experimental alloy (Figure 4) exhibits only one strong peak during heating/cooling cycle related to the extensive melting and re-solidification of $\alpha-\mathrm{Mg}$ solid solution, respectively. However, two strong signals were reported to be clearly observed for other alloys of Mg-Al-Zn system such as AZ61 and AZ91 alloy ${ }^{11,13}$. These researches reported that the second signal at about $437^{\circ} \mathrm{C}$ in thermal analysis of $\mathrm{AZ}$ alloy series with higher $\mathrm{Al}$ content 


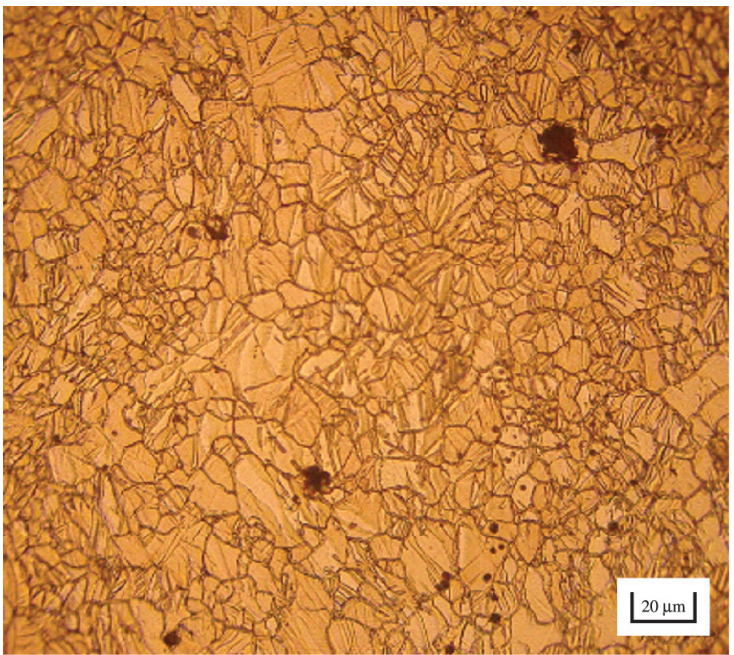

(a)

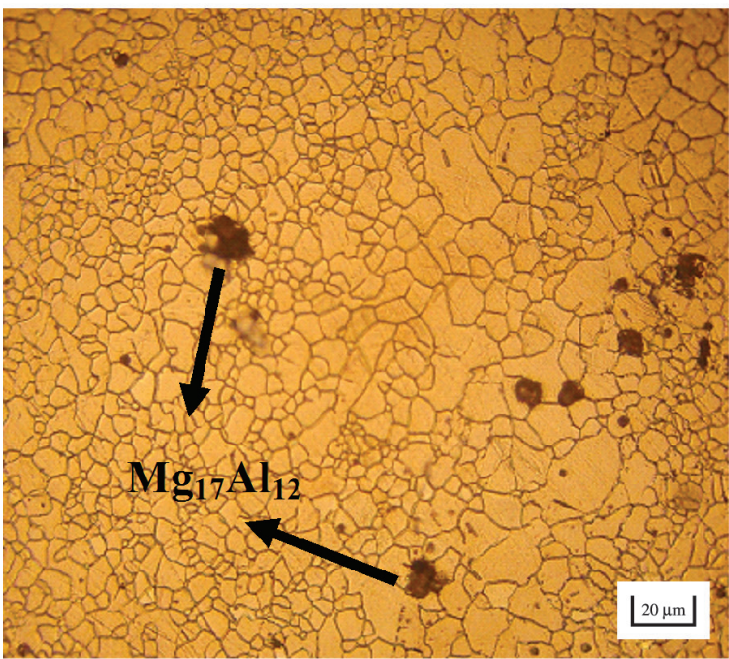

(c)

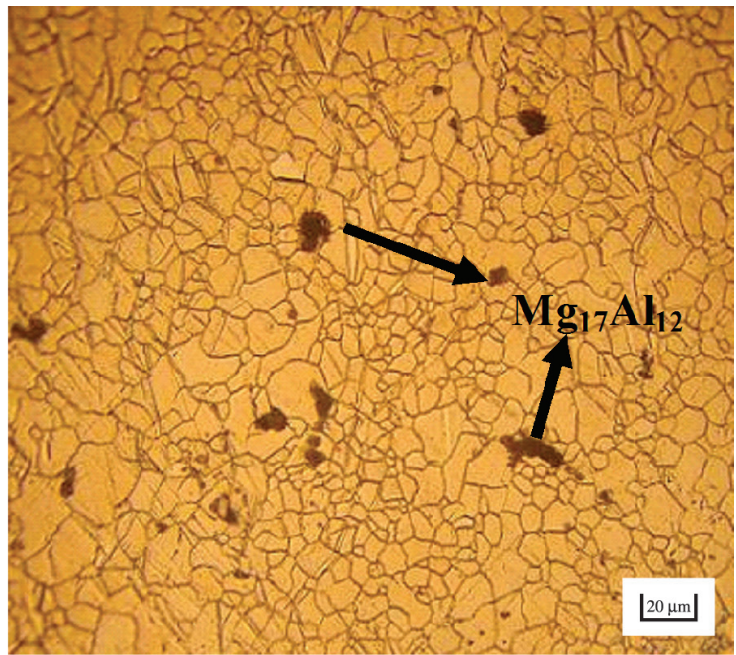

(b)

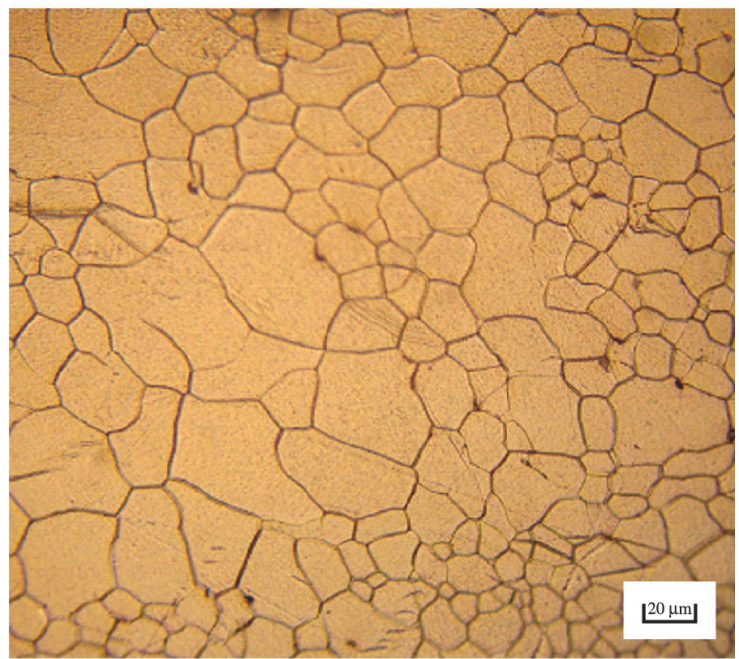

(d)

Figure 2. (a) The as received initial microstructure, (b) homogenized microstructure at $420{ }^{\circ} \mathrm{C} / 3 \mathrm{hr}$, (c) $420{ }^{\circ} \mathrm{C} / 6 \mathrm{hr}$ and (d) $420{ }^{\circ} \mathrm{C} / 12 \mathrm{hr}$.

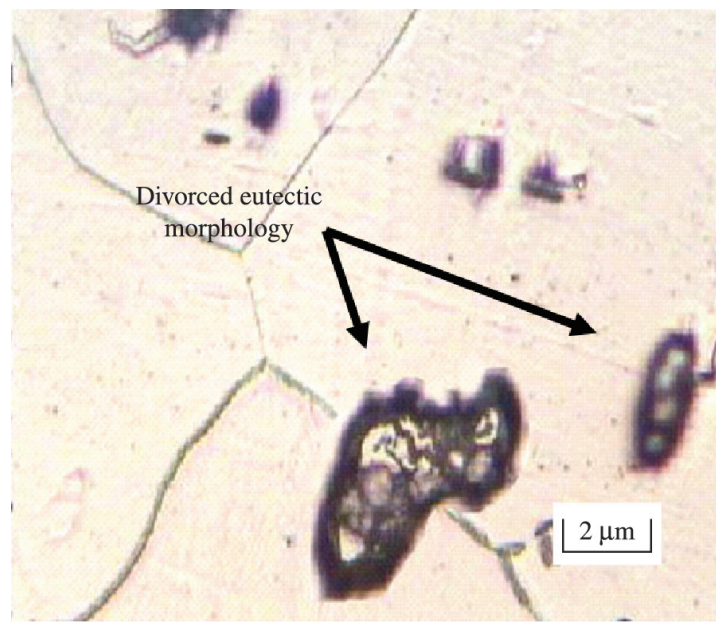

(a)

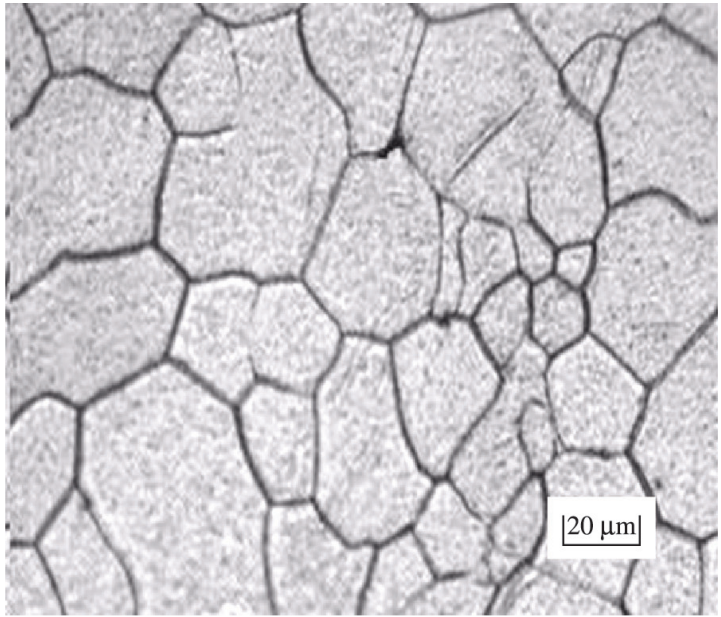

(b)

Figure 3. The homogenized microstructure at (a) $450{ }^{\circ} \mathrm{C} / 5 \mathrm{~min}$ and (b) $475{ }^{\circ} \mathrm{C} / 5 \mathrm{~min}$. 
may be attributed to the precipitation of $\gamma$ phase under the non-equilibrium cooling condition (Scheil condition) and $\gamma$ eutectic melting reaction during subsequent equilibrium heating.

The solidification curve of experimental alloy (the variation of liquid fraction versus temperature), which was calculated under equilibrium conditions (solid line) as well as Scheil condition (dashed line), are shown in Figure 5. As is seen the liquid fraction markedly decreases as $\alpha-\mathrm{Mg}$ solid solution phase forms at about $630{ }^{\circ} \mathrm{C}$. In equilibrium condition, the solidification ends at about $575{ }^{\circ} \mathrm{C}$, but in non-equilibrium condition a kink (arrowed in Figure 5) is observed at about $431{ }^{\circ} \mathrm{C}$ which closely corresponds to the precipitation of $\gamma$ phase under Scheil conditions.

The specific solid content $f_{s}$ of experimental alloy which is mostly $\gamma$ eutectic phase can be calculated according to Scheil's equation ${ }^{14}$ :

$$
f_{s}=1-\left\{\left(T_{m}-T\right) /\left(T_{m}-T_{L}\right)\right\}^{-1 /\left(1-k_{0}\right)}
$$

Where $T_{m}$ is the melting temperature of pure metal, $\mathrm{T}_{\mathrm{L}}$ is the liquidus temperature and $k_{0}$ is the equilibrium distribution coefficient of the alloy. The volume fraction of $\gamma$ eutectic phase in non-equilibrium solidification state of experimental alloy is estimated to be about $1.7 \%$. As is

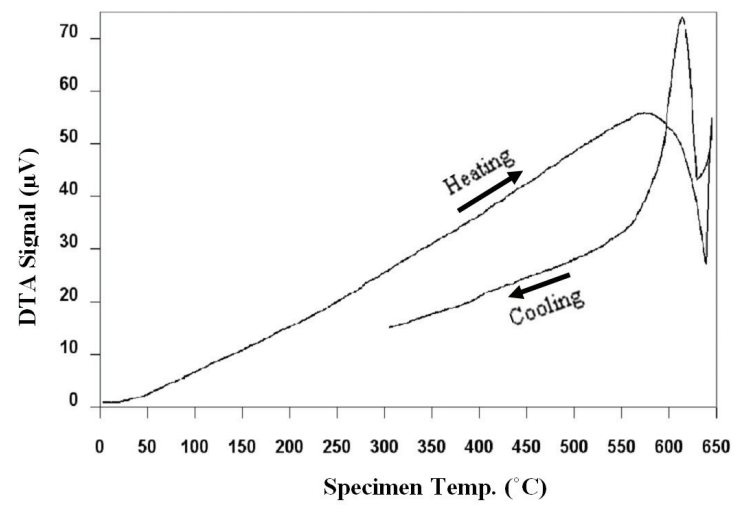

Figure 4. The DTA curve of AZ31 alloy (The heating/cooling rate is $5 \mathrm{~K} / \mathrm{min}$ ).

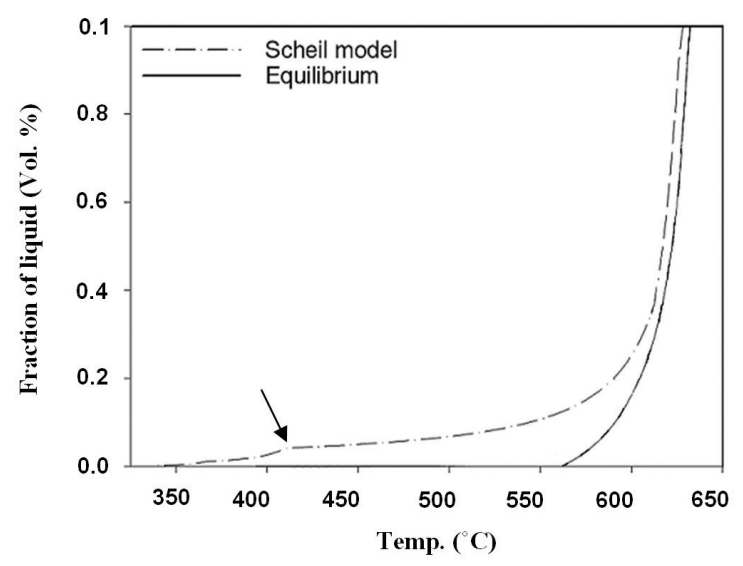

Figure 5. The calculated solidification behavior of the experimental alloy; Equilibrium (solid line) and Scheil (dashed line) conditions. reported, a complete mixture in liquid state and a negligible diffusion in the solid are considered in Scheil model ${ }^{15}$. Therefore the real values of $f_{s}$ should be smaller than that of calculated one. Thus, it may be deduced that in contrast to the AZ61 and AZ91 alloys, due to small volume fraction of $\gamma$ precipitates in AZ31 Mg alloy, no significant signal related to precipitation of $\gamma$ phase or $\gamma$ eutectic melting would be detected. A similar behavior was observed in thermal analysis curve of AM50 magnesium alloy ${ }^{16}$. However, solidification process of $\mathrm{Mg}-\mathrm{Al}-\mathrm{Zn}$ system is far from an equilibrium condition even at extremely slow cooling rate of $1 \mathrm{~K} / \mathrm{min}^{11}$, and coring in $\alpha-\mathrm{Mg}$ solid solution occurs and $\gamma$ phase forms in the microstructure of $\mathrm{Mg}-\mathrm{Al}$ alloys with down to about $2 \mathrm{wt}$. $\% \mathrm{Al}^{17}$. It is worth mentioning that the coring occurs even in alloy with $0.01 \%$ solute atom ${ }^{18}$. Consequently, even though in the present DTA no peaks of $\gamma$ eutectic phase could be monitored, still the local formation of this phase is anticipated.

Accordingly, the observed semi-divorced morphology of $\gamma$ eutectic phase in homogenized microstructure at $450{ }^{\circ} \mathrm{C}$ for $5 \mathrm{~min}$ (Figure $3 \mathrm{a}$ ) can be discussed relying on the partial melting of $\gamma-\mathrm{Mg}_{17} \mathrm{Al}_{12}$ phase. This is due to the eutectic melting reaction which is appeared to occur at $\sim 437{ }^{\circ} \mathrm{C}$. Increasing the temperature to $450{ }^{\circ} \mathrm{C}$ (just higher than the eutectic temperature of experimental alloy), local melting occurs by the inverse eutectic reaction of the $\gamma$-phase region with the surrounding $\alpha$-phase matrix.

The microstructure of the specimen which was homogenized at $475^{\circ} \mathrm{C}$ for $5 \mathrm{~min}$ is shown in Figure $3 \mathrm{~b}$. Further increasing the temperature to $475{ }^{\circ} \mathrm{C}$ (above melting point of $\gamma$ precipitates $\sim 462{ }^{\circ} \mathrm{C}$ ), the incipient melting of $\gamma$ particles may be completed. This would be ended to a homogenized single phase microstructure. The dissolution of melted eutectic precipitates can be estimated based on the thermodynamic calculation. The dissolution kinetics of plate-shaped melted eutectic films at any given temperature can be evaluated using Whelan method ${ }^{19}$ (see the Appendix A). In this way the time required for dissolution of a plate shaped liquid film and spherical liquid droplets are determined by the following equations, respectively:

$$
B=B_{0}-\frac{k}{\sqrt{\pi}} \sqrt{D t}
$$

$R=R_{0}-\sqrt{k D t}$

Where $B$ is half the thickness of the liquid film, $k$ is the thermodynamic driving force for dissolution and $D$ is the solute diffusion coefficient for a given temperature. The times required for dissolution of $\gamma$ phase, at various temperatures of 450,475 and $500{ }^{\circ} \mathrm{C}$, were calculated and plotted against film thickness in Figure 6. Therefore it is concluded that in thermomechanical processing during soaking time at the test temperature, may not provide adequate time for melting and dissolution of $\gamma$ phase in matrix. Thus the presence of partially melted $\gamma$ phase may results in the strain concentration, reduced elongation and premature fracture.

In according to the above discussion, the eutectic reaction and incipient melting of $\gamma$ phase are occurred during thermomechanical treatments. This imposes a detrimental 
effect on hot workability of AZ31 alloy. This may be considered as a rationale for previously reported formability change in AZ31. The ductility data of AZ31 alloy reported in the literature for the hot rolled ${ }^{20}$ and as-cast condition ${ }^{21}$ have been used to re-plot the ductility-temperature curve as shown in Figure 7. As is clearly realized the ductility reduces

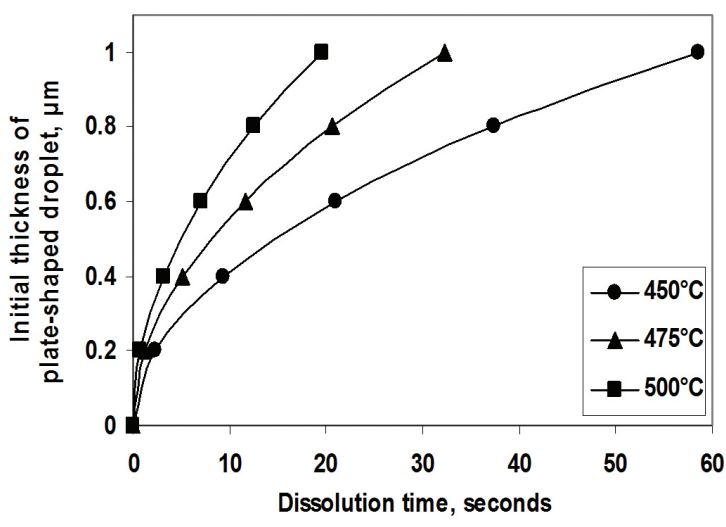

Figure 6. The dissolution time of $\gamma$ films at different temperatures.

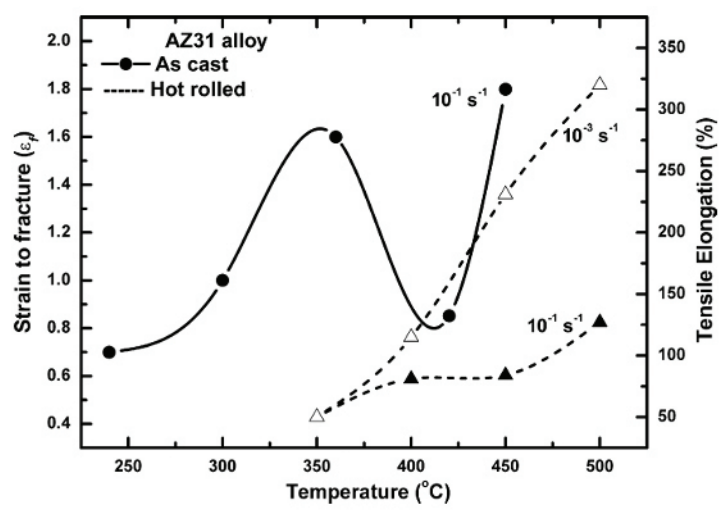

Figure 7. The re-plotted variation of ductility as a function of temperature for as-cast ${ }^{21}$ and hot rolled ${ }^{20} \mathrm{AZ} 31$ alloys.

\section{References}

1. Li Z, Dong J, Zeng XQ, Lu C and Ding WJ. Influence of $\mathrm{Mg} 17 \mathrm{Al12}$ intermetallic compounds on the hot extruded microstructures and mechanical properties of $\mathrm{Mg}-9 \mathrm{Al}-1 \mathrm{Zn}$ alloy. Materials Science and Engineering: A. 2007; 466(1-2):134-139. http://dx.doi.org/10.1016/j. msea.2007.02.029

2. Huang X, Suzuki K, Watazu A, Shigematsu I and Saito N. Effects of Homogenization Treatment on Mechanical Properties of Hot-Rolled AZ31 Magnesium Alloy. Materials Science Forum. 2007; 561-565:255-258. http://dx.doi. org/10.4028/www.scientific.net/MSF.561-565.255

3. Quan GZ, Shi Y, Wang YX, Kang BS, Ku TW and Song WJ. Constitutive modeling for the dynamic recrystallization evolution of AZ80 magnesium alloy based on stress-strain data. Materials Science and Engineering: A. 2011; 528(28):80518059. http://dx.doi.org/10.1016/j.msea.2011.07.064 at around $\sim 437{ }^{\circ} \mathrm{C}$ and strain rate of $0.1 \mathrm{~s}^{-1}$ for the as-cast condition; whereas it increases as higher temperatures. In the case of wrought AZ31 alloy, the increase in ductility is also minimal under similar deformation conditions (400- $\left.450{ }^{\circ} \mathrm{C} / 0.1 \mathrm{~s}^{-1}\right)$. In agreement with the results of present work the observed ductility drop is attributed to the partial melting of $\gamma$ phase due to the eutectic melting reaction of $\alpha+\gamma \rightarrow \mathrm{L}$.

In contrast, it is shown that at lower strain rates $\left(<10^{-3} \mathrm{~s}^{-1}\right)$, the hot rolled AZ31 alloy exhibits superplasticity and the ductility increases monotonically by temperature. In addition no sharp transition from lower to higher ductility is seen. It should be noted that the effect of second $\gamma$ phase on workability and optimum deformation conditions of the alloy is strongly influenced by strain rate and prior history. However, as is well established the phenomenon of highstrain-rate super-plasticity (HSRS) can be related to the formation of thin, liquid-phase layers at interfaces or grain boundaries $^{22}$. Moreover, for present experimental alloy it was previously shown by two of present authors that at temperature higher than $460^{\circ} \mathrm{C}$, locally melted $\gamma$ phase acts as a lubricant in compressive deformation regimes. This in turn serves to relax the stress concentrations caused by the dislocations piles-up thereby resulting in flow acceleration of the solid under lubricated flow mechanism ${ }^{23}$.

\section{Conclusion}

In the present work, considering the eutectic temperature of AZ31 alloy, homogenization treatment was performed below and higher than the eutectic melting temperature of $\gamma$ precipitates through different homogenization times. The results indicated that the dissolution rate of $\gamma$ phase is very low even at temperatures just below the eutectic point of the alloy in solid state, whereas is dramatically increased at temperatures higher than eutectic point where melting of $\gamma$ precipitates is commenced. The ductility drop which had been observed in ductility-temperature curve of AZ31 alloy at $\sim 437{ }^{\circ} \mathrm{C}$ was rationalized relying on the partial melting of $\gamma-\mathrm{Mg}_{17} \mathrm{Al}_{12}$ phase due to inverse eutectic reaction.

4. Spigarelli S, Mehtedi ME, Cabibbo M, Evangelista E, Kaneko $\mathrm{J}$, Jäger A et al. Analysis of high-temperature deformation and microstructure of an AZ31 magnesium alloy. Materials Science and Engineering: A. 2007; 462(1-2):197-201. http://dx.doi. org/10.1016/j.msea.2006.03.155

5. Al-Samman $\mathrm{T}$ and Gottstein G. Dynamic recrystallization during high temperature deformation of magnesium. Materials Science and Engineering: A. 2008; 490(1-2):411-420. http:// dx.doi.org/10.1016/j.msea.2008.02.004

6. Zhang KF, Yin DL and Wu DZ. Formability of AZ31 magnesium alloy sheets at warm working conditions. International Journal of Machine Tools and Manufacture. 2006; 46(11):1276-1280. http://dx.doi.org/10.1016/j.ijmachtools.2006.01.014

7. Prasad $Y$ and Rao KP. Processing maps for hot deformation of rolled AZ31 magnesium alloy plate: anisotropy of hot workability. Materials Science and Engineering: A. 2008; 487(1-2):316-327. http://dx.doi.org/10.1016/j. msea.2007.10.038 
8. Zhu T, Chen ZW and Gao W. Incipient melting in partially melted zone during arc welding of AZ91D magnesium alloy. Materials Science and Engineering: A. 2006; 416(1-2):246252. http://dx.doi.org/10.1016/j.msea.2005.10.032

9. Lü YZ, Wang QD, Ding WJ, Zeng XQ and Zhu YP. Fracture behavior of AZ91 magnesium alloy. Materials Letters. 2000; 44(5):265-268. http://dx.doi.org/10.1016/S0167$577 \mathrm{X}(00) 00041-0$

10. Lin DL, Zeng XQ, Ding WJ, Jin L and Mao DL. Effect of second phase on the mechanical properties of Mg-Al-Zn alloy by equal channel angular extrusion. Materials Science Forum. 2007; 546-549:249-252. http://dx.doi.org/10.4028/www. scientific.net/MSF.546-549.249

11. Ohno M, Mirkovic D and Schmid-Fetzer R. Liquidus and solidus temperatures of $\mathrm{Mg}$-rich $\mathrm{Mg}-\mathrm{Al}-\mathrm{Mn}-\mathrm{Zn}$ alloys. Acta Materialia. 2006; 54(15):3883-3891. http://dx.doi. org/10.1016/j.actamat.2006.04.022

12. Brooks CR. Heat treatment, structure, and properties of nonferr ous alloys. Ohio: American Society for Metals; 1982.

13. Ohno M, Mirkovic D and Schmid-Fetzer R. Phase equilibria and solidification of $\mathrm{Mg}$-rich $\mathrm{Mg}-\mathrm{Al}-\mathrm{Zn}$ alloys. Materials Science and Engineering: A. 2006; 421(1-2):328-337. http:// dx.doi.org/10.1016/j.msea.2006.02.006

14. Czerwinski F. Near-liquidus molding of $\mathrm{Mg}-\mathrm{Al}$ and $\mathrm{Mg}-\mathrm{Al}-\mathrm{Zn}$ alloys. Acta Materialia. 2005; 53(7):1973-1984. http://dx.doi. org/10.1016/j.actamat.2005.01.009

15. Mingbo Y, Fusheng P, Renju Ch and Liang B. Effect of semi-solid isothermal heat treatment on the microstructure of Mg-6A1-1Zn-0.7Si alloy. Journal of Materials Processing Technology. 2008; 206:374-381

16. Mirković D and Schmid-Fetzer R. Solidification curves for commercial $\mathrm{Mg}$ alloys determined from differential scanning calorimetry with improved heat-transfer modeling. Metallurgical and Materials Transactions A. 2007; 38(10):25752592. http://dx.doi.org/10.1007/s11661-007-9237-z

17. Dahle AK, Lee YC, Nave MD, Schaffer PL and StJohn DH. Development of the as-cast microstructure in magnesiumaluminium alloys. Journal of Light Metals. 2001; 1(1):61-72. http://dx.doi.org/10.1016/S1471-5317(00)00007-9

18. Reed-Hill RE and Abbaschian R. Physical metallurgy principles. New York: Van Nostrand Princeton; 1964.

19. Yamamoto M, Gerlich A, North TH and Shinozaki K. Cracking in the stir zones of Mg-alloy friction stir spot welds. Journal of Materials Science. 2007; 42(18):7657-7666. http://dx.doi. org/10.1007/s10853-007-1662-2

20. Wu X and Liu Y. Superplasticity of coarse-grained magnesium alloy. Scripta Materialia. 2002; 46(4):269-274. http://dx.doi. org/10.1016/S1359-6462(01)01234-9

21. Myshlyaev MM, McQueen HJ, Mwembela A and Konopleva E. Twinning, dynamic recovery and recrystallization in hot worked $\mathrm{Mg}-\mathrm{Al}-\mathrm{Zn}$ alloy. Materials Science and Engineering: A. 2002; 337(1-2):121-133. http://dx.doi.org/10.1016/S09215093(02)00007-2

22. Higashi K, Nieh TG, Mabuchi M and Wadsworth J. Effect of liquid phases on the tensile elongation of superplastic aluminum alloys and composites. Scripta Metallurgica et Materialia. 1995; 32(7):1079-1084. http://dx.doi.org/10.1016/0956716X(94)00003-Z

23. Chino Y, Kobata M, Iwasaki H and Mabuchi M. An investigation of compressive deformation behaviour for AZ91 $\mathrm{Mg}$ alloy containing a small volume of liquid. Acta Materialia. 2003; 51(11):3309-3318. http://dx.doi.org/10.1016/S13596454(03)00162-9 


\section{Appendix A}

Figure A.1 shows the binary $\mathrm{Mg}-\mathrm{Al}$ equilibrium phase diagram. The driving force for diffusion and dissolution of liquid droplets is determined by the relation:

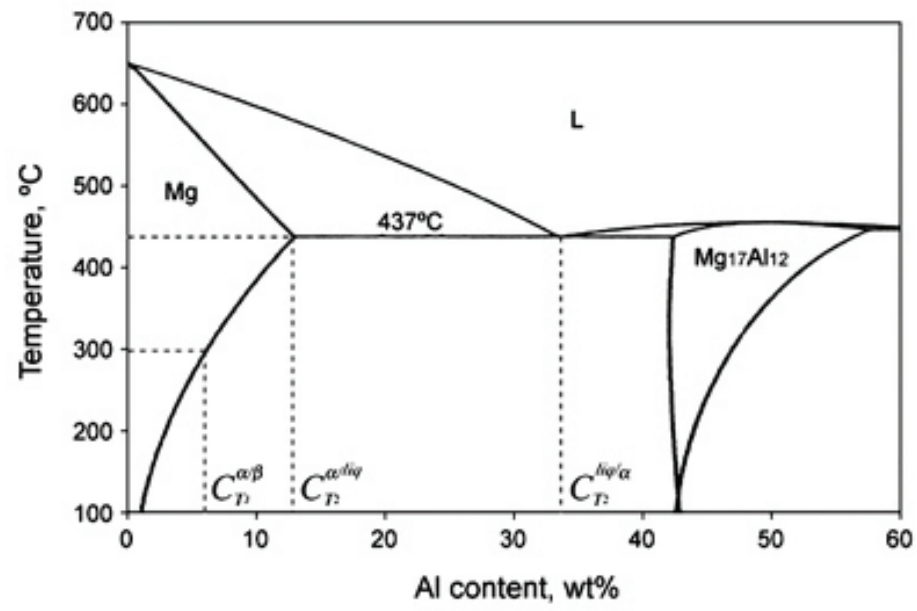

Figure A1. $\mathrm{Mg}$-rich portion of the binary $\mathrm{Mg}-\mathrm{Al}$ equilibrium phase diagram.

$k=\left[\frac{C_{T_{2}}^{\alpha / l i q}-C_{T_{1}}^{\alpha / \beta}}{C_{T_{2}}^{\text {liq/ }}-C_{T_{2}}^{\alpha / l i q}}\right]$

For AZ31:

$K=1.0, C_{T_{1}}^{\alpha / \beta}=3 \%, C_{T_{2}}^{\alpha / l i q}=13 \%, C_{T_{2}}^{l i q / \alpha}=33 \%, T_{2}=710 \mathrm{~K}$

The diffusion coefficient depends on temperature as is follows:

$D=D_{0} \exp \left[-\frac{Q}{R T}\right]$

Where $\mathrm{R}=8.314 \times 10^{-3} \mathrm{~kJ} /(\mathrm{mol} \mathrm{K})$ and the diffusion rate of $\mathrm{Al}$ in $\mathrm{Mg}$ is ${ }^{11}$ :

$D_{0}=1.53 \times 10^{7} \mu \mathrm{m}^{2} / \mathrm{s}, \mathrm{Q}=125 \mathrm{~kJ} / \mathrm{mol}$

For AZ31:

$\mathrm{D}_{\mathrm{Al} \text { in } \mathrm{Mg}}=1.42 \times 10^{-2} \mu \mathrm{m}^{2} / \mathrm{s}$ at $450{ }^{\circ} \mathrm{C}$

$\mathrm{D}_{\mathrm{Al} \mathrm{in} \mathrm{Mg}=} 2.85 \times 10^{-2} \mu \mathrm{m}^{2} / \mathrm{s}$ at $475^{\circ} \mathrm{C}$

$\mathrm{D}_{\mathrm{Al} \mathrm{in} \mathrm{Mg}=} 5.46 \times 10^{-2} \mu \mathrm{m}^{2} / \mathrm{s}$ at $500^{\circ} \mathrm{C}$ 